\title{
Europe bids for molecular biology 'club'
}

[MUNICH] The European Molecular Biology Organization (EMBO), which promotes molecular biology through fellowships, conferences and workshops, is to launch a series of young investigator awards.

EMBO hopes that the five-year awards will be sufficiently prestigious to encourage the brightest young scientists to install themselves permanently in laboratories across Europe. Those eligible must be within eight years of completing their $\mathrm{PhD}$.

The intention is that EMBO Research Scientists, as the recipients of the awards will be called, will form a 'club' of top-level molecular biologists who will maintain links with each other and with research group leaders at the European Molecular Biology Laboratory (EMBL) in Heidelberg, Germany, for at least the duration of the fellowships.

The governments of EMBO's 23 member states, which operate collectively as the European Molecular Biology Conference, last week agreed in principle to finance the scheme. If all goes smoothly, they will decide on its permanent level of financing in 2000.

EMBO is expected to launch the scheme by contributing ECU500,000 (US\$590,000) of its current budget annually into a pool of funds, which is expected to be expanded by donations from other sources such as charities and foundations. Some member countries will also be expected to contribute to this pool, the largest contributions coming from the richer countries.

EMBO Research Scientists will be given a salary, the costs of running a small laboratory conducting research independent of the host institute's tenured scientists, and travel expenses associated with 'networking' attending an annual meeting and visiting other laboratories in the 'club'.

Some candidates would already be receiving national young investigator awards. They would receive no support from EMBO for salaries and laboratory costs, but would receive full support for networking.

Any member state wishing to increase its number of EMBO Research Scientists in this category could do so by making a further payment. This could be used to top up the resources of all the EMBO Research Scientists in that country if the national young investigator award is judged to be significantly lower than the European average.
A second category would be selected in the first instance by EMBO. The relevant member state would agree the choice of candidate and pay a significant proportion of salary and running costs. The remainder would come from the EMBO awards pool.

"EMBO's selection committee will ensure the high standard of selected Research Scientists, and ensure that their quality is uniform throughout Europe," says Frank Gannon, director of EMBO. "I expect the initiative will become an important component of scientific life in Europe, one which identifies high-quality researchers at an early stage in their careers, and helps us to keep such individuals in Europe."

Maria Carmo Fonseca, a professor of cell and molecular biology at the University of Lisbon, who previously worked at EMBL, says the strong networking component will be particularly helpful in attracting back to "peripheral" countries, such as Portugal and Spain, young scientists who trained abroad.

The Portuguese Ministry of Research has already agreed to set up a young investigator award scheme that will allow it to exploit the EMBO scheme, she says.

Alison Abbott

\section{South Korean researchers under fire for claims of human cloning}

[токуо] A South Korean research team, which announced last week that it had cloned a human embryo, has been criticized by other researchers for refusing to disclose the evidence to back up its claim.

Indeed, many doubt whether the cloning experiment, claimed to be the first to have produced an embryo from a human somatic cell, has produced promising results.

Researchers from Kyunghee University Hospital in Seoul announced at a press conference that they had cultivated an earlystage embryo using an unfertilized egg and a somatic cell from a female patient who had been receiving infertility treatment there.

The team, led by Kim Seoung Bo and Lee Po Yon, professor and associate professor in obstetrics and gynaecology at Kyunghee University, injected nuclei from granulosa cells (differentiated cells that surround the oocyte) into enucleated oocytes.

Of six fertilized eggs, one divided to the four-cell stage. Researchers say they then destroyed this 'embryo' without implanting it into a human body. They say they adapted the technique used by researchers from the University of Hawaii, who have cloned several generations of mice using granulosa cells (see Nature 394, 369-373; 1998).

"The experiment was carried out purely for the purpose of medical research, and not for clinical purposes. The fertilized egg was not implanted in the uterus of the donor, as

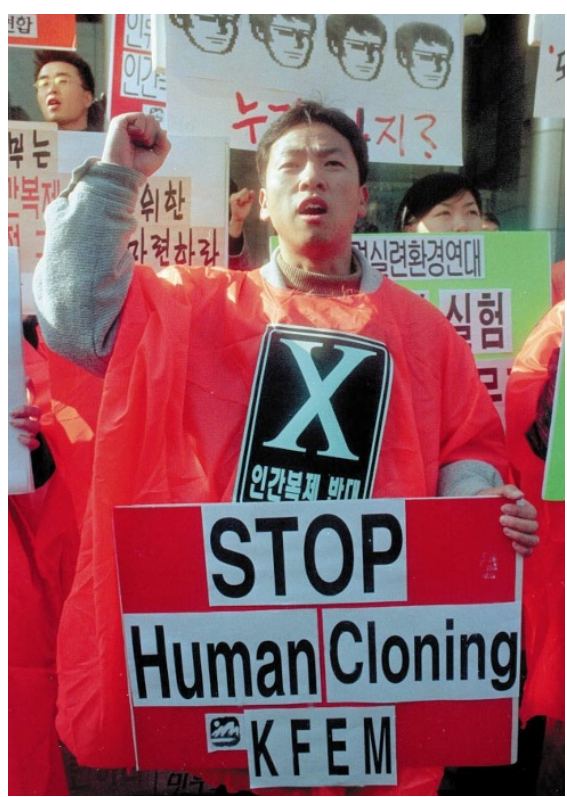

compiling a draft bill on the regulation of human cloning research, which is expected to pass the congress early next year.

Although the research team has no plans for any further experiments until the new legislation is ready, it hopes to use the technique to develop cells and tissues for replacement therapy and to treat infertility.

But there is widespread concern among the public, even though the experiment stopped short of producing a full human clone. The Korean Federation for the Environment Movement, for example, says human cloning research, if misused, could result in a "great mishap to all mankind".

There was a more muted response from the scientific community in South Korea, with some doubting its success, as no evidence has been released.

"The lack of a scientific presentation leads us to think that their results are not 'hair raising' in terms of a scientific breakthrough," says Dae-Young Uhm, associate professor in physiology at Sungkyunkwan University. "The only notable social response was from the civil rights groups."

Kim refuses to release evidence of the experiment's success to avoid further controversy. "We have strong evidence, including photos, but we will not release it now as we believe our reputation has been damaged enough," he says. Asako Saegusa 